\title{
O catálogo editorial e a bibliografia como fontes de pesquisa: avanços e desafios na era digital
}

\author{
Publishing catalog and bibliography as research sources: advances and challenges in the \\ digital age
}

Willian Eduardo Righini de Souza

Doutorando em Ciência da Informação pela Escola de Comunicações e Artes da Universidade de São Paulo -

ECA/USP.

E-mail : wrighini@yahoo.com.br

\begin{abstract}
Resumo
Ao contrário de países como França e Inglaterra, o Brasil não possui uma tradição de publicação de bibliografias comerciais correntes ou públicas nacionais que permitam averiguar a produção nacional de livros por longos períodos, ainda que o depósito legal seja uma realidade há mais de um século. As nossas principais bibliografias foram interrompidas ou perderam continuidade após alguns anos, dificultando a realização de pesquisas sobre determinados períodos históricos. Atualmente, o Brasil não dispõe de uma bibliografia nacional corrente e a Biblioteca Nacional enfrenta dificuldades para manter os seus registros eletrônicos atualizados. Nesta perspectiva, defende-se que os catálogos editoriais podem contribuir para pesquisas ao permitir a constituição de listas bibliográficas, embora, na maioria das vezes, não adotem um vocabulário controlado para facilitar a recuperação dos seus registros. Com o advento do digital, diversas editoras têm substituído a produção de catálogos impressos pela disponibilização de registros online. Assim sendo, aborda-se, a partir deste quadro, o catálogo editorial e a bibliografia com fontes de pesquisa assim como se discute os avanços e desafios para a produção desses instrumentos na contemporaneidade.
\end{abstract}

Palavras-chave: Catálogo editorial. Bibliografia nacional. Bibliografia corrente.

\begin{abstract}
Unlike countries like France and England, Brazil does not have a publishing tradition of current commercial or national public bibliographies in order to verify the domestic production of books for long periods, although the legal deposit is a reality for more than a century. Our main bibliographies were discontinued or lost continuity after a few years, making it difficult to conduct research on certain historical periods. At present, Brazil does not have a current national bibliography and the national library is struggling to keep their electronic records updated. In this perspective, it is argued that publishing catalogs can contribute to researches to allow the creation of bibliographies, although in most cases, do not adopt a controlled vocabulary to facilitate the retrieval of their records. With the advent of digital, several publishers have replaced the production of printed catalogs by providing online records. Therefore, we discuss, from this framework, the publishing catalog and the bibliography as research sources as well as analyze the progress and challenges for the production of these instruments nowadays.
\end{abstract}

Keywords: Publishing catalog. National bibliograpgy. Current bibliography.

InCID: R. Ci. Inf. e Doc., Ribeirão Preto, v. 7, n. esp., p. 202-223, ago. 2016.

DOI: 10.11606/issn.2178-2075.v7iespp202-223 


\section{Introdução}

O foco deste trabalho é discutir a importância de catálogos e bibliografias para a pesquisa acadêmica e apontar, a partir de observações empíricas, mudanças que estão ocorrendo nesses instrumentos com o advento do digital. Porém, antes, entendemos que é preciso distinguir dois tipos de catálogos. De acordo com Beaudiquez (1983, p. 45), eles podem ser tanto uma lista organizada de fontes de informação para fins de localização em um acervo quanto uma lista, na maioria das vezes ilustrada, de mercadorias à venda, tendo como função a propaganda. No primeiro caso, o catálogo de biblioteca é o exemplo mais comum. No segundo, encontramos os catálogos de supermercados, lojas, entre outros estabelecimentos comerciais, que pouco parecem se relacionar com a pesquisa acadêmica. Contudo, neste grupo ainda se incluem os catálogos editoriais, criados para divulgar as obras de uma editora perante bibliotecários, professores, livreiros e leitores em geral. Assim sendo, neste artigo, consideramos essas duas possibilidades, explicitando o adjetivo editorial quando necessária à diferenciação.

Também visamos abordar a disponibilidade de bibliografias comerciais e públicas no Brasil, especialmente as nacionais, que poderiam complementar ou mesmo dispensar a consulta a catálogos editoriais para o conhecimento dos títulos publicados por uma editora em determinado período de tempo. Para uma melhor noção das deficiências brasileiras, apontamos algumas iniciativas internacionais bem-sucedidas na compilação de listas de livros e, potencialmente, outros materiais, como partituras e CD-ROMs. Reconhecemos que apresentamos uma visão parcial, já que diversas bibliografias online são de acesso restrito e não tivemos a oportunidade de consultá-las. De todo modo, acreditamos que podemos contribuir em complemento às atuais abordagens sobre o tema.

Nossas reflexões surgiram, sobretudo, durante a escrita da tese de doutorado intitulada "O livro de bolso na contemporaneidade: a experiência brasileira e os principais modelos internacionais", defendida em 2016 na Escola de Comunicações e Artes da Universidade de São Paulo. Nela, priorizamos a análise em quatro coleções: as brasileiras L\&PM Pocket, da L\&PM, e Companhia de Bolso, da Companhia das Letras, e as francesas Le Livre de Poche, da La Librairie Générale Française, e Folio, da Gallimard. Como um dos nossos objetivos era analisar as características bibliográficas dos livros de bolso lançados nos últimos anos, ou seja, número de páginas, dimensões, capas, etc., as primeiras dificuldades surgiram ao procurar pelos catálogos editoriais de algumas coleções. Onde encontrá-los? As bibliotecas 
não têm o hábito de colocá-los em circulação, afinal, geralmente, são vistos apenas como impressos promocionais, material de divulgação e não fontes de pesquisa e informação para o público. O bibliotecário até pode preservá-los para o trabalho de seleção de acervo, mas o interesse dos usuários por este tipo de impresso é menos evidente. A consulta direta ao arquivo das editoras, no caso de sua existência, apresenta-se praticamente impossível, considerando que, muitas vezes, elas não vislumbram o acesso de terceiros à sua documentação e temem que informações estratégicas sejam obtidas pela concorrência. Por fim, resta-nos o contato com as editoras solicitando os seus últimos catálogos. Todavia, em nossa experiência, a resposta mais frequente é de que elas não possuem exemplares para envio ou que todos os registros estão disponíveis em seu site, não sendo mais produzidas versões impressas.

\section{Catálogos editoriais}

Nos últimos anos, editoras têm substituído a criação de material de divulgação impresso por ações na Internet, seja por economia quanto pelas possibilidades que as novas tecnologias oferecem. Cada vez mais, elas investem na apresentação de seus sites institucionais e criam perfis nas redes sociais, como Facebook, Twitter e Instagram, utilizando-os tanto para a divulgação de lançamentos, como para promoções, informações sobre eventos e atendimento aos consumidores. No caso da editora L\&PM, do Rio Grande do Sul, um catálogo em formato e-book é oferecido, porém a maioria das editoras apenas inserem informações sobre os títulos no site conforme eles são lançados. A Folio também dispõe de uma lista no formato pdf (portable document format) com todas as suas obras; entretanto, como são elencados apenas os títulos, autores e preços divididos por séries, tornou-se inviável utilizá-la para obter todas as informações que procurávamos.

Para a venda, a Internet apresenta muito mais flexibilidade, seja pela quantidade de informações disponibilizadas como pela opção de comprar os livros com apenas alguns cliques. Em um catálogo editorial online, trechos dos livros são frequentemente oferecidos para download, as capas podem ser visualizadas em alta resolução e os registros estruturados como hipertextos, remetendo a informações sobre outros títulos do mesmo autor, gênero ou série. Há ainda de se considerar que muitos livros possuem uma versão digital, a única em alguns casos, que pode ser adquirida dentro de alguns minutos pelo site institucional ou livrarias virtuais. Nesse sentido, o catálogo impresso perde parte do seu atrativo, parecendo 
limitado e rapidamente desatualizado. Qual o custo-benefício de se divulgar um livro digital em um catálogo impresso se o leitor precisará recorrer à Internet para adquiri-lo? Não seria economicamente e estrategicamente mais vantajoso utilizar o canal de venda também para a divulgação? Algumas plataformas de venda de livros digitais, como Amazon e Kobo, até oferecem o primeiro capítulo gratuitamente na expectativa de que o leitor comece a ler e adquira os demais. Em suma, a Internet dispõe de muito mais conteúdo para o consumidor escolher as suas leituras do que os tradicionais catálogos impressos.

$\mathrm{Na}$ tentativa de adquirir o catálogo impresso 2012 das quatro coleções que investigamos, obtivemos sucesso apenas com a L\&PM Pocket. Sendo assim, devido a essas condições, decidimos seguir as recomendações das próprias editoras e consultar os registros de suas obras no catálogo online. A partir deste momento, percebemos que, dependendo dos objetivos do consulente, esses catálogos podem apresentar diversos inconvenientes. A primeira dúvida foi quais registros estavam realmente disponíveis para consulta. Embora os sites das editoras contivessem diversos títulos esgotados e esta informação estivesse visível, obras mais antigas e fora do circuito comercial há anos não estavam presentes nos catálogos online de algumas coleções. As razões para tal exclusão também não era exposta. A justificativa poderia ser que o site continha apenas os títulos lançados após a sua criação ou então que foram excluídos do sistema aqueles que estavam fora do catálogo na última atualização. Caso o consulente não cruze as informações com aquelas oferecidas, por exemplo, por uma biblioteca nacional, ele pode ser levado a acreditar que tem ao seu alcance a lista completa de todos os títulos.

Embora a maioria das editoras insira a data de lançamento de um título em seu catálogo online, a sua organização por data não é tão evidente quanto quando há lançamentos anuais de um catálogo impresso. Vários sites tendem a não apresentar todos os seus livros em listas por data, mas organizá-los segundo suas séries/coleções. Como as páginas são atualizadas constantemente, torna-se necessário consultar todos os links das séries/coleções para separar aquelas de um determinado período. Porém, em alguns casos, outro problema surge, que é o mesmo livro aparecer em mais de uma divisão classificatória. Nem todas as editoras possuem séries/coleções bem delineadas. Algumas vezes, como observamos na L\&PM e não ser raro em editoras infantis, os títulos são organizados por temas e uma mesma obra pode se encaixar em mais de um grupo. Neste caso, o consulente precisa redobrar a atenção para identificar registros duplicados. 
O catálogo editorial e a bibliografia como fontes de pesquisa: avanços e desafios na era digital

Esses exemplos reforçam que o objetivo do catálogo editorial online é a divulgação dos lançamentos para o aumento das vendas, não existindo uma grande preocupação com os sistemas de classificação e controle de vocabulário para uma recuperação mais precisa dos registros. O mesmo ocorre com os portais de comércio online: as pesquisas são realizadas por palavras do título, do registro ou, como a Livraria Cultura já testou, por marcação de tags pelo próprio consumidor.

Para Wenz (2009, p. 49), a principal contribuição dos catálogos comerciais online é a integração do cliente. Desde o final dos anos 1990, com o desenvolvimento da Web 2.0, grandes empresas têm permitido que os seus clientes avaliem, comentem e classifiquem os livros. A Amazon, por exemplo, ainda divulga as notas que os títulos receberam (de uma a cinco estrelas) e facilita a visualização dos comentários segundo diferentes critérios. Assim sendo, o consumidor pode abrir mão de consultar amigos e o livreiro para conhecer diferentes opiniões sobre uma obra, bastando comparar centenas delas pela Internet.

Devido a uma maior familiaridade com a interface gráfica e a opção de comprar um exemplar, muitos leitores acabam preferindo procurar informações sobre um livro nos sites de venda do que no catálogo de uma biblioteca. Somente depois de definir quais os seus títulos de interesse que ocorre a verificação de sua disponibilidade na biblioteca mais próxima. Acreditando nesta preferência, a British Library, na Inglaterra, recorreu a uma aplicação web (mashup) para que usuários da Amazon fossem informados da disponibilidade de um título em seu acervo quando geolocalizados na mesma região (WENZ, 2009, p. 53). Em contrapartida, em 2011, diversos registros da British Library continham links para o site da Amazon, o que gerou protestos de livrarias independentes (BRITISH..., 2011). O mesmo acontece no WorldCat, o maior catálogo bibliográfico online do mundo, com links para diversas livrarias online.

A British Library possui um catálogo online bastante rico em conteúdo por registro e opções de busca. Um registro, além dos campos mais tradicionais, como autor, título e descrição física, ainda pode conter resumo da obra, sumário, capa em boa resolução, biografia do autor, link para o Google Preview, lista de universidades que possuem um exemplar, espaço para comentários e tags dos usuários, preço de capa, entre outros. De modo geral, o catálogo desta biblioteca possui muito mais informações de que um catálogo editorial ou de livraria online. Além do catálogo geral da British Library, vários catálogos temáticos são disponibilizados com textos explicativos e imagens. Ao pesquisar por um termo, a lista de 
descritores utilizada na catalogação é visualizada. Mesmo assim, a biblioteca reconhece que muitos usuários ainda preferem pesquisar informações sobre títulos em sites como Amazon ou metabuscadores como Google.

Se o catálogo online de editoras e lojas não é elaborado considerando a sua possível utilidade como fonte de pesquisa, os catálogos impressos, embora possuam os mesmos objetivos, conseguem ser mais claros em sua organização devido à própria estrutura linear da obra impressa. Ainda que existam diferentes formas de apresentação dos títulos, como por assunto, autor e série, eles são dispostos progressivamente, não criando confusão em relação ao critério adotado em determinado trecho. O pesquisador pode utilizar apenas a seção que lista os títulos por autor, por exemplo, ignorando outros critérios de ordenamento sem grandes problemas. Ele também saberá, de antemão, qual o período coberto pelo catálogo e em qual ano ele foi produzido, enquanto que, na Internet, nem sempre é possível descobrir em que data um livro foi registrado e com quais outros. Se a hipertextualidade e a atualidade da Internet beneficiam a navegação e estimulam a interatividade, a linearidade das informações de um catálogo impresso facilita a interpretação dos dados e preserva um retrato fiel da lista de títulos de uma editora em um determinado ano.

Muitas das informações obtidas em um catálogo editorial online são pós-coordenadas. Elas não estão evidentes à priori, mas podem ser recuperadas a partir da estratégia de busca. A princípio, esta possibilidade parece favorável ao usuário, mas revela os seus limites devido à falta de controle no preenchimento dos campos e oferecimento de instrumentos auxiliares, como tesauros. No catálogo online da L\&PM, não é possível pesquisar por data de lançamento, mas mesmo que esta opção estivesse disponível, sua utilidade seria questionável, pois vários registros não contêm esta informação. Outro empecilho é verificado na pesquisa por gênero, pois embora o campo de busca exista, não há controle e instruções de uso. Para os livros de Agatha Christie, por exemplo, que constitui uma das maiores séries, não há padrão na indicação dos gêneros: em alguns títulos, é utilizado "policial, literatura estrangeira"; em outros, "policial, literatura moderna internacional, ficção estrangeira"; e em um terceiro grupo, somente "policial". Desse modo, todo resultado representa sempre apenas uma fração das obras que poderiam ser recuperadas pelo descritor.

Para a formação de coleções, o bibliotecário encontra diversas vantagens nas novas tecnologias de informação. Em alguns catálogos online, como o da Companhia das Letras, o leitor pode inserir comentários, ajudando o profissional a se informar sobre a recepção e 
O catálogo editorial e a bibliografia como fontes de pesquisa: avanços e desafios na era digital

público potencial de uma obra. Semanalmente, a mesma editora publica no Facebook os lançamentos do período, sendo mais uma oportunidade para ler comentários e conhecer os novos títulos. Pelas redes sociais, ela também divulga o andamento para a preparação de futuros lançamentos, como trechos de tradução, críticas do tradutor e datas atualizadas da previsão para o seu oferecimento no mercado. Com os catálogos impressos, nem sempre o bibliotecário os recebia, muitas vezes precisava solicitar mais de uma vez o seu envio, o material poderia tornar-se obsoleto com rapidez e era necessário esperar um longo tempo até receber uma nova edição. Hoje, as atualizações são em tempo real.

Por outro lado, caso assim desejasse, embora saibamos que não fosse uma prática comum, os catálogos impressos poderiam ser incluídos no acervo e preservados ano após ano, tornando muito mais simples para um pesquisador conhecer o desenvolvimento de uma coleção, as datas em que determinadas séries surgiram, o número de títulos por período e a divisão por gêneros, enquanto que, nos dias de hoje, com informações sendo publicadas de maneira fragmentada, várias delas em redes sociais nas quais os dados são efêmeros, não há muitas garantias de preservação nem de recuperabilidade.

A proposta da L\&PM de disponibilizar um catálogo em e-book constitui-se uma solução intermediária, pois evita os gastos com impressão, mas mantém a estrutura de um catálogo impresso. De fato, a sua versão e-book é uma cópia da versão impressa. Entretanto, permanece a dúvida sobre a perenidade desses registros. Um pesquisador terá acesso às edições digitais dos anos anteriores? Pelo o que podemos verificar em seu site, apenas a edição corrente está online.

O catálogo impresso ou em e-book tende a se assemelhar a um livro convencional, possuindo uma organização que ajuda melhor compreender a importância de uma série ou título para a editora. Em uma estrutura linear, quais são as primeiras séries apresentadas? Qual a quantidade de páginas reservadas para cada uma delas? É comum, em catálogos impressos, alguns títulos serem destacados, com reprodução de capas em maior tamanho e descrições mais detalhadas. Em alguns casos, um único título pode ocupar uma página inteira. Em um catálogo em preto e branco, algumas informações/ilustrações podem ser coloridas. A capa e a contracapa do catálogo também podem servir de indícios para a confirmação de hipóteses. $\mathrm{Na}$ capa do seu catálogo 2012, a L\&PM Pocket utilizou rostos de autores amplamente conhecidos. Posteriormente, ao analisar as capas e elementos paratextuais de todos os seus 
títulos, confirmamos que a popularidade de um autor é frequentemente utilizada na divulgação de um lançamento, inclusive utilizando a sua foto como ilustração da capa.

O catálogo impresso é um produto acabado da editora, com um projeto gráfico específico para o ano do seu lançamento. A cada novo catálogo, uma nova capa, um conjunto de títulos a ser destacado, talvez um novo papel e formato. Com os catálogos online, que tendem a ser modificados conforme o lançamento de um título, a análise por recortes temporais se mostra mais complexa, já que toda consulta reflete o estado atual da coleção. Títulos mais antigos também podem ser retirados do catálogo sem que o usuário perceba. Quando não há preservação dos registros, perde-se parte da história do desenvolvimento de uma coleção ou editora.

\section{As bibliografias comerciais e correntes}

Se os catálogos editoriais não são produzidos considerando sua possível contribuição para a pesquisa, as bibliografias comerciais correntes poderiam suprir esta lacuna. Seu surgimento remonta ao século XVI, quando alguns editores começaram a oferecer o seu catálogo na Feira do Livro de Frankfurt, Alemanha. Sendo assim, possui a mesma origem dos catálogos editoriais. Malclés (1956, p. 54; 71) lembra que os catálogos editoriais são utilizados há séculos como fontes para a produção de repertórios. Graças, em parte, aos catálogos editoriais distribuídos nas feiras de Frankfurt e Leipzig, que os alemães Johann Cless e Georg Draud conseguiram publicar, em 1611, a Bibliotheca Librorum Germanicarum Classica. O mesmo fez Theophili Georgi para lançar, entre 1742 e 1758, em cinco volumes, a sua Allgemeines Europäisches Bücher-Lexikon.

Todavia, enquanto o catálogo editorial é utilizado, principalmente, para a divulgação de lançamentos perante o leitor/ comprador, a bibliografia comercial corrente voltou-se para profissionais do mercado (editores, livreiros, autores, etc.), bibliotecários e pesquisadores. Enquanto o primeiro prioriza a divulgação e venda, o segundo também apresenta uma grande preocupação com o controle bibliográfico e não se limita a uma única editora. Ainda que os catálogos editorias possam ser vistos como bibliografias comerciais, estabelecemos esta diferenciação ao encontrarmos significativas diferenças entre eles no que diz respeito aos seus objetivos e público final. 
O catálogo editorial e a bibliografia como fontes de pesquisa: avanços e desafios na era digital

O controle bibliográfico tornou-se uma ferramenta da indústria editorial para, com o auxílio da atribuição de um número único a cada obra (ISBN - International Standard Book Number), acompanhar o ritmo e diversidade de lançamentos, os números de venda, a variação de preços, consultar informação atualizada sobre disponibilidade e, por último, assessorar distribuidores e livreiros no comércio do livro (URBANO SALIDO, 2000, p. 169).

Segundo Beaudiquez (1983, p. 116-117), as bibliografias correntes devem ter como características: uma periodicidade regular e curta (semanal ou mensal), evitando um grande período de tempo entre o lançamento de um título e o seu recenseamento; fornecer todas as descrições necessárias para a aquisição de um documento; ser exaustiva e ter um preço acessível para a compra por bibliotecas. Na maioria dos países, quem assume este compromisso são editoras comerciais, que publicam obras de referência e revistas profissionais. A autora cita como exemplos os Bowker ${ }^{1}$ e H. W. Wilson ${ }^{2}$, nos Estados Unidos, e o Cercle de la Librairie ${ }^{3}$, na França, que oferecem bibliografias correntes de acesso pago.

No Brasil, podemos apontar pelo menos duas iniciativas privadas na metade do século XX: a Bibliografia Nacional, lançada pelo bibliógrafo Antonio Simões dos Reis entre 1942 e 1943; e o Boletim Bibliográfico Brasileiro, criado pelo escritor José Cruz Medeiros entre 1952 e 1964. O primeiro projeto foi abandonado após o décimo-sexto volume. O segundo contou com doze volumes, divididos em duas fases: a primeira, entre 1952 e 1958, indicava apenas as referências bibliográficas; a segunda, entre 1958 e 1964, já com o subtítulo Revista de Editores, trazia resenha da bibliografia brasileira em organização sistemática, reportagens e artigos sobre literatura, entrevistas, pesquisas de mercado, etc. (MACHADO, 2003, p. 63-64). Outra proposta de curta duração foi a Edições Brasileiras, produzida pelo Sindicato Nacional dos Editores de Livros (SNEL) entre 1963 e 1966. A periocidade era trimestral e possuía duas seções: Novidades e Livros em Estoque. Os números eram organizados "pela ordem alfabética das editoras, com índices onomástico (de autores e tradutores) e biblionímico e também incluindo notícias e anúncios de livros novos” (FONSECA, 1972, p. 11).

No final da década de 1960, mais especificamente em 1968, a editora Vozes, de Petrópolis, deu início à Bibliografia Classificada, publicação que pretendia listar todos os livros e revistas publicados no Brasil. A editora esperava contar com a colaboração dos

\footnotetext{
${ }^{1}$ Disponível em: 〈http://www.bowker.com/>. Acesso em: 01 ago. 2015.

${ }^{2}$ Disponível em: <http://www.hwwilsoninprint.com/>. Acesso em: 01 ago. 2015.

${ }^{3}$ Disponível em: <http://www.cercledelalibrairie.org/>. Acesso em: 01 ago. 2015.
} 
editores nacionais, o que não aconteceu, levando ao encerramento do projeto no final do mesmo ano, em seu nono número. Em 1973, foi a vez do editor J. Heydecker, da editora Atlantis Ltda., criar Livros Novos, uma compilação de lançamentos universitários que excluía livros didáticos e escolares. As obras eram arranjadas por assunto/tema, de acordo com a CDU (Classificação Decimal Universal). Voltada para o mercado, os registros incluíam o número de encomenda dos livros. Não encontramos na literatura disponível a data de encerramento de mais esta iniciativa (CALDEIRA; CARVALHO, 1980, p. 214).

Ao contrário de outros países, a principal bibliografia corrente brasileira foi elaborada por um órgão público, o Instituto Nacional do Livro (INL). Nos períodos de 1938 a 1955 e de 1962 a 1967, o INL foi o editor da Bibliografia Brasileira. Em 1956, o Instituto lançou a Revista do Livro, que passou a exercer esta função. A revista interrompeu suas publicações em 1970, retomando em 2002. Depois de mais um intervalo, entre 2010 e 2014, ela foi relançada em 2015, já sem a bibliografia corrente, mas voltada para o oferecimento de artigos acadêmicos sobre livros e bibliotecas. Em 1968, foi criada a Bibliografia Brasileira Mensal, que segundo Machado (2003, p. 63), apresentava "as referências bibliográficas obedecendo a uma ordem sistemática, índices onomásticos e biblionímicos e ainda uma lista de periódicos e de editoras". Em 1972, ela também foi encerrada.

Como se vê, apesar de algumas iniciativas isoladas, o Brasil não possui uma tradição de bibliografias comerciais correntes duradouras nem de revistas profissionais que divulgam os lançamentos com regularidade. Os principais projetos foram tentativas de compensar a incapacidade da Biblioteca Nacional em manter uma publicação atualizada e constante dos seus registros. Porém, sem estrutura e apoio, elas também sucumbiram. Em 2015, o Brasil não possuía editoras que publicavam o repertório de livros lançados mensalmente ou anualmente no país.

Outros países, contudo, ainda contam com publicações que revelam a utilidade deste trabalho. Na França, desde 1847, profissionais do livro estão reunidos na associação Cercle de la Librairie para defender seus interesses e elaborar produtos sobre o estado do mercado livreiro. Desde 1972, o Cercle é o responsável por emitir o ISBN dos livros publicados no país. A partir de setembro de 1979, a associação passou a publicar a revista semanal Livres Hebdo e a mensal Livres de France, cujo repertório de lançamentos é idêntico ao suplemento Livres du Mois da Livres Hebdo. A diferença está no acréscimo de reportagens (BEAUDIQUEZ, 1983, p. 117). 
O catálogo editorial e a bibliografia como fontes de pesquisa: avanços e desafios na era digital

A Livres Hebdo não foi a primeira bibliografia comercial francesa, surgindo da fusão da Bibliographie de l'Empire français ou Journal général de l'imprimerie et de la librairie 4 (1811) e do Bulletin du Livre (1958), este último similar a uma revista com repertório bibliográfico. A editora Hachette também criou a sua bibliografia corrente, a Biblio Mensuel, que existiu de 1933 a 1972. Deste modo, são viáveis pesquisas com dados exatos sobre os títulos publicados no país ao longo dos séculos XIX ao XXI. A consulta às revistas ainda possibilita o estudo dos anúncios editoriais, a análise das principais discussões do período, pois elas possuem reportagens sobre o mercado, a verificação da lista dos mais vendidos e de diversos gráficos sobre vendas. A Livres Hebdo, em específico, publica números temáticos regulares, como sobre o mercado de livros de bolso uma vez por ano, entrevistando editores, especialistas e autores, apresentando as variações em relação ao ano anterior, entre outros conteúdos que constituem uma rica fonte de pesquisa. Em razão desta diversidade e quantidade de informações, seria possível um estudo sobre o mercado de livros de bolso na França consultando apenas os diversos dossiês anuais da revista sobre o tema.

No que se refere aos repertórios, a Livres Hebdo dispõe de dois: um para os livros a serem lançados no mês seguinte e outro para os títulos lançados na semana. O primeiro, conforme explicita a revista, não é definitivo, pois as editoras podem mudar datas, preços ou mesmo cancelar uma publicação. Os títulos são organizados por editoras, dispostas em ordem alfabética. A partir desta organização inicial, eles são elencados por previsão de lançamento. Cada registro possui o título, a indicação de responsabilidade, incluindo nomes de tradutores e ilustradores, edição, publicação, descrição física, ISBN, preço e gênero. O segundo e mais importante repertório lista todos os livros publicados na França naquela semana. Eles são organizados por temas/áreas do conhecimento, juntamente com o seu número correspondente na CDD (Classificação Decimal de Dewey), em ordem alfabética. Todos os registros possuem título, indicação de responsabilidade, edição, publicação, descrição física, série, pequeno resumo, preço e ISBN com código de barras. Quando o livro é no formato bolso, insere-se um pequeno símbolo indicativo.

Livros de um domínio específico podem conter informações complementares: títulos de não ficção indicam que são destinados ao público geral ou a especialistas/professionais; já

\footnotetext{
${ }^{4}$ A partir de 1814, a Bibliographie de l'Empire français ou Journal général de l'imprimerie et de la librairie passou a se chamar Bibliographie de la France, permanecendo com este nome até 1990. A partir de 1990, ela se transformou em Bibliographie nationale française. No início dos anos 2000, sua publicação em papel foi substituída pela versão online.
} 
livros ficcionais podem destacar a partir de qual idade a obra deve ser lida. São excluídos desse repertório livros pagos pelo autor, pago pelo autor em parceria com uma editora, edições oferecidas exclusivamente por correspondência e clube do livro, livros digitais e aqueles impressos sob demanda. São disponibilizados entre cerca de 800 e 1300 registros por semana. Ao final, é possível consultar um índice de autores.

Se um instrumento similar existisse no Brasil, poderíamos ter substituído a consulta inicial aos sites das editoras e utilizado um repertório para identificar e listar todos os títulos de bolso já lançados pelas coleções que avaliávamos. Entretanto, cabe ponderar que o simples acesso a essa lista não garante a sua utilidade, visto que o arranjo dos títulos em bibliografias impressas nem sempre corresponde às necessidades do pesquisador. Como os livros na Livres Hebdo estão organizados por área/tema, os títulos de bolso estão misturados a livros de tamanho convencional e separados de suas coleções. Apenas a verificação de todos os registros permitiria destacá-los do conjunto. Considerando que, por semana, mais de 1000 livros podem ser lançados, esta separação seria bastante demorada em uma pesquisa que tem como objeto diversas coleções durante um longo período de tempo. A Livres Hebdo tem o mérito de incluir um símbolo ao lado de cada livro de bolso, mas inúmeros outros critérios de busca poderiam não ser contemplados pelo arranjo atual. O benefício da versão impressa é uma maior certeza do registro de todos os títulos, não existindo o risco de atualização do banco de dados como ocorre nos catálogos editoriais online.

Há alguns anos, a Livres Hebdo oferece o acesso a essas informações em sua página na Internet. Por depender de uma assinatura mensal, não pudemos consultá-la. Porém, caso existam diversos campos para a busca, a dificuldade de lidar com o seu grande acervo de registros poderia ser amenizada. Bastaria realizar a busca cruzando o nome da coleção com os anos a serem investigados. A possibilidade de pós-coordenar informações seria uma vantagem considerável desde que houvesse controle de vocabulário, facilitando a recuperação dos registros relevantes. Ainda assim, permanece o problema do preenchimento dos campos, pois caso não sejam de preenchimento obrigatório, o vocabulário controlado não será suficiente para garantir o acesso a todos os dados. Em se tratando de bibliografias, que tem como projeto a cobertura total dos títulos publicados em um país, domínio, especialidade ou período, o seu oferecimento online exige cuidados redobrados para impedir resultados que sugiram uma falsa completude. 
Assim como a França e os Estados Unidos, o Reino Unido também possui um serviço de bibliografia comercial corrente, administrado pela Nielsen, empresa responsável pela atribuição do ISBN e oferecimento do Books in Print, um repertório online de livros em venda $^{5}$. A empresa dispõe de duas opções de assinatura: uma destinada ao mercado dos EUA e outra de cobertura global com foco na língua inglesa. Até 2002, a Whitaker \& Sons Ltd., adquirida pela Nielsen, publicava uma versão impressa da bibliografia corrente, que chegava a possuir mais de 15 mil páginas na cobertura de um ano, e atribuía o ISBN no Reino Unido. A justificativa de priorizar uma versão online foi conciliar a confiabilidade do serviço com as diversas possibilidades de busca oferecidas pelo digital. Em versão impressa, a Nielsen publica a revista The Bookseller, criada em 1858 por Joseph Whitaker com o título A Handbook of British and Foreign Literature. A The Bookseller pode ser considerada a versão inglesa da Livres Hebdo, oferecendo notícias e análises do mercado, entrevistas, lista semanal dos mais vendidos, incluindo e-books, a profissionais do livro e da biblioteca. Em contrapartida, desde 2004, não possui o repertório semanal dos livros publicados na região.

Na Itália, a produção da bibliografia comercial corrente está sob responsabilidade da Informazioni Editoriali ${ }^{6}$, criada em 1985. Ela publica o banco de dados Alice, que cobre os livros italianos em venda, e o e-kitāb, para livros digitais em venda. Através do banco de dados, também é possível consultar livros que já estão esgotados e os próximos lançamentos. Ele dispõe de mais de 400 mil capas de livros em duas resoluções. O assinante pode exportar os dados conforme os campos selecionáveis da descrição bibliográfica: autor, título, tradutor, número de páginas, preço, entre outros. Uma das opções é recuperar todos os títulos que foram descritos como de bolso. Para a nossa pesquisa, poderíamos selecionar os campos formato, série e ano para produzir um repertório de coleções de bolso italianas. Em seu site, pode-se fazer o download do tesauro utilizado na representação temática, indicando a preocupação com o controle de vocabulário. Ao todo, a Informazioni Editoriali possui registro de $99,08 \%$ dos títulos disponíveis no mercado, o que corresponde a cerca de 60 mil lançamentos por ano.

Diferente dos casos acima citados, a Espanha, assim como o Brasil, não conta com um histórico de bibliografias comerciais correntes. Desde 1972, quando foi criada a Agencia Española del ISBN, a elaboração de bibliografias comerciais sempre foi feita pelo Estado,

\footnotetext{
${ }^{5}$ Disponível: <http://www.booksinprint.com/>. Acesso em: 01 ago. 2015.

${ }^{6}$ Disponível: $\langle$ http://www.ie-online.it/ $>$. Acesso em: 01 ago. 2015.
} 
primeiro através do Instituto Nacional del Libro Español (INLE) e depois, a partir de 1998, por meio do Centro de Documentación del Libro, la Lectura y las Letras Españolas, ambos pertencentes ao Ministério da Cultura. A partir dos dados enviados pelas editoras, uma base de dados é oferecida gratuitamente, permitindo buscas por título, autor, língua, etc., similar ao catálogo da Biblioteca Nacional do Brasil. São oferecidos apenas 11 campos de busca, excluindo, por exemplo, preço, consulta de capas e distinção entre livros de bolso e de tamanho convencional.

Desde 1973, a Agencia Española del ISBN publicava os Libros Españoles em Venta, contendo o repertório anual dos livros publicados no país. Contudo, ele foi abandonado nos anos 2000 em prol do acesso online exclusivo. Como produto anual, o Observatorio de la Lectura y el Libro, também do Ministério da Cultura, divulga o Panorámica de la Edición Española de Libros, com dados gerais sobre a evolução do setor. Em seu site ${ }^{7}$, o consulente ainda pode encontrar dados estatísticos sobre a divisão dos títulos daquele ano por língua, tema, número de páginas, entre outros.

Para pesquisadores, o melhor instrumento de pesquisa é a Bibliografía Española, publicada pela Biblioteca Nacional e elaborada a partir de todas as obras que entram em seu acervo, ou seja, não é uma bibliografia comercial, mas pública nacional. Oferecida no formato impresso entre 1959 e 2006, ganhou uma versão em CD-ROM a partir de 1992 (retrospectiva desde 1976), existindo até 2007, quando foi substituída pelo acesso online exclusivo. A Bibliografía Española cobre todos os periódicos, monografias, mapas e registros musicais catalogados pela Biblioteca Nacional, que recebe exemplares de todas as publicações do país por meio do depósito legal. O site ${ }^{8}$ oferece busca por assunto, através da Classificação Decimal Universal (CDU), palavras e índices de autor, título, matéria e série. É possível consultar todas as obras catalogadas por mês/ano, seja pela busca no site quanto pelos arquivos em pdf referentes a cada mês. Como o repertório é realizado a partir da catalogação, a bibliografia do mês de abril, por exemplo, ainda possui títulos publicados no ano anterior. Os registros se resumem a fichas bibliográficas no padrão ISBD, com opção de visualização no formato MARC, ISO2709 e XML.

A Espanha, na linha de outros países europeus, também possui revistas voltadas para o mercado livreiro, porém, apenas a El libro Español, publicada mensalmente pelo Instituto

\footnotetext{
${ }^{7}$ Disponível em: <http://www.mecd.gob.es/cultura-mecd/areas-cultura/libro/mc/pee $>$. Acesso em: 01 ago. 2015.

${ }^{8}$ Disponível em: <http://www2.bne.es/BEL_publico/>. Acesso em: 01 ago. 2015.
} 
O catálogo editorial e a bibliografia como fontes de pesquisa: avanços e desafios na era digital

Nacional del Libro Español entre 1958 e 1986, contava com o repertório dos lançamentos. As revistas mais recentes, como De Libros, possuem apenas reportagens, resenhas e análises. Deste modo, embora não se encontre em uma condição preocupante, não há na Espanha a mesma variedade de fontes para pesquisar o desenvolvimento do mercado editorial como encontramos na França, Reino Unido e Estados Unidos ${ }^{9}$.

Segundo Urbano Salido (2000, p. 170), os produtos e serviços da Agencia Española del ISBN são bastante criticados por empresas e profissionais do livro pelas inconsistências dos dados bibliográficos assim como pela falta de informações sobre disponibilidade e preço. O Estado, inclusive, já tentou transferir a responsabilidade do controle bibliográfico para associações privadas, que criariam um sistema de autogestão, porém as partes ainda não conseguiram chegar a um acordo satisfatório.

\begin{abstract}
Estas insuficiencias en la información sobre novedades, la poca fiabilidad de muchos de los registros que aparecen, así como la pobre información sobre el contenido y la tipologia de los documentos repertoriados, contrasta vivamente con los productos que hoy por hoy se muestran en numerosos catálogos editoriales y de librerías por Internet (URBANO SALIDO, 2000, p. 174).
\end{abstract}

No Brasil, durante a pesquisa, surgiram algumas ferramentas para a medição do comércio de livros. Em 2012, a empresa alemã Gfk começou a colher dados das vendas no varejo (livrarias, supermercados, etc.) e no comércio online. Por meio dos seus relatórios é possível consultar os gêneros mais populares, o montante de vendas, o preço médio do livro, as oscilações por categoria, entre outros. Na metade de 2013, foi a vez da Nielsen desembarcar no país. O seu serviço é similar ao da Gfk: a partir dos dados de venda das livrarias, comercio online e demais varejistas, ela produz relatórios semanais com o ranking de vendas, faturamento, preço tabela, preço médio, etc. Segundo o Painel de Vendas de Livros no Brasil, publicado pelo Sindicato Nacional dos Editores de Livro (SNEL) e pela Nielsen em abril de 2015, a Nielsen cobre atualmente apenas $63 \%$ dos vendedores de livros, incluindo os canais online (NIELSEN; SNEL, 2015). Todavia, outros levantamentos já feitos pela Câmara Brasileira do Livro, Associação Nacional de Livrarias e SNEL eram ainda mais limitados, pois abrangiam apenas associados.

Não há como negar que a chegada da Gfk e Nielsen ao Brasil podem trazer inúmeros benefícios para o planejamento das editoras. Porém, é importante lembrar que a maior parte

\footnotetext{
9 Nos Estados Unidos, a revista sobre livros mais conhecida é a Publishers Weekly: http://www.publishersweekly.com/. Acesso em 01 ago. 2015.
}

InCID: R. Ci. Inf. e Doc., Ribeirão Preto, v. 7, n. esp., p. 202-223, ago. 2016. 
dos dados organizados não é pública, mas reservada às editoras que assinam o serviço. Sendo assim, pesquisadores não tem acesso a este material. Ao mesmo tempo, ele não é uma lista de livros, mas relatórios semanais para o acompanhamento das vendas. Enquanto para o editor essas informações são valiosas e poderiam contribuir com pesquisas se os dados fossem mais acessíveis, elas não substituem a contribuição de bibliografias. Por ser uma iniciativa recente, as empresas também não cobrem a totalidade ou quase dos vendedores, sendo um retrato apenas aproximado. Ainda serão necessários alguns anos para avaliar os efeitos dessas ferramentas nas práticas editoriais e como elas podem colaborar para uma maior divulgação do funcionamento do mercado e das características das coleções.

Com a disponibilidade de dados em linha, cresce a pressão para uma maior variedade de informações sobre as obras, como capas, sumários, resumos e links para outros registros. A mesma expectativa surge em relação aos catálogos de biblioteca, que precisam se tornar mais atrativos e eficazes para competir com os catálogos de plataformas de venda. Indicamos que esta modernização já é realidade em bibliotecas nacionais como a British Library, que estabeleceu parcerias até com a Amazon. Contudo, além de ser uma exceção, já que muitos dos campos citados não estão presentes na maioria dos catálogos de bibliotecas, o processo de busca ainda se apresenta de difícil compreensão para muitos usuários, desestimulando seu uso. Mesmo um bibliotecário pode preferir consultar sites comerciais ao catálogo da Biblioteca Nacional para ter acesso a mais dados para a sua seleção de materiais.

\section{A bibliografia nacional por depósito legal}

Como, atualmente, o Brasil não possui bibliografias comerciais correntes nem retrospectivas, ainda resta uma alternativa para o pesquisador: o controle bibliográfico realizado pela Biblioteca Nacional. Como salienta Campello (2006, p. 9), as bibliotecas foram as primeiras instituições a se preocuparem com o controle bibliográfico ao produzirem catálogos. A diferença principal entre o catálogo e a bibliografia propriamente dita é que enquanto o primeiro é voltado para o acervo da instituição, a segunda pode conter registros de todo um país ou tentar informar todas as fontes sobre um tema, embora saibamos hoje que, mesmo com o auxílio do ISBN, alguns materiais não serão descritos.

Em 1977, a UNESCO (Organização das Nações Unidas para a Educação, a Ciência e a Cultura), em parceria com a IFLA (International Federation of Library Associations and 
O catálogo editorial e a bibliografia como fontes de pesquisa: avanços e desafios na era digital

Institutions), apresentou as diretrizes para o programa conhecido como Controle Bibliográfico Universal (CBU), "cujo objetivo era reunir e tornar disponíveis os registros da produção bibliográfica de todos os países" (CAMPELLO, 2006, p. 12). Nesse sentido, cada país, recorrendo às novas tecnologias de informação, deveria providenciar uma descrição bibliográfica padronizada de sua produção nacional e disponibilizá-la para a comunidade. Um projeto que precisaria do apoio das editoras e da cooperação entre bibliotecas para ser bemsucedido.

Com o Controle Bibliográfico Universal e o seu acesso em rede, um usuário poderia consultar o registro de qualquer obra no mundo com rapidez e de forma padronizada. Desde 1990 ligado ao projeto MARC (Machine Readable Cataloging), este controle também permite o intercâmbio de dados entre bibliotecas e favorece a catalogação cooperativa.

Como o CBU depende de um controle nacional, tanto a UNESCO quanto a IFLA sugerem a criação de uma Agência Bibliográfica Nacional (ABN) em cada país para aplicar as recomendações e coordenar a produção dos registros bibliográficos a partir de normas e códigos internacionais, como o Código de Catalogação Anglo-Americano (AACR), a Descrição Bibliográfica Internacional Normalizada (ISBD), o Número Internacional Normalizado para Livros (ISBN) e o Número Internacional Normalizado para Publicações Seriadas (ISSN). A Agência também deve garantir o cumprimento do depósito legal.

No Brasil, desde o decreto $\mathrm{n}^{\circ} 433$ de 1847, as editoras são obrigadas a depositar pelo menos um exemplar de suas produções na Biblioteca Nacional e podem ser punidas caso não o façam. De acordo com Grings e Pacheco (2010, p. 79), em 1805, as oficinas tipográficas portuguesas já enviavam uma cópia de suas publicações para a Real Biblioteca, prática que se estendeu à Imprensa Régia com a Independência do Brasil. A partir do decreto 1825 de 1907, instituiu-se a Biblioteca Nacional com única responsável pelo recolhimento. Segundo a redação atual da lei, o depósito deve ser realizado em até 30 dias após sua publicação. Caso contrário, as editoras podem ser multadas em até 100 vezes o valor da obra no mercado e ter exemplares apreendidos para a concretização do depósito (BRASIL, 2004).

O país se destaca no cenário internacional por possuir uma biblioteca nacional desde 1810, quando Dom João VI transferiu a Real Biblioteca da Ajuda de Lisboa para o Rio de Janeiro em razão da fuga da corte após a invasão napoleônica, e contar com um dos dez maiores acervos do mundo, com cerca de dez milhões de itens. Contudo, a falta de investimentos e políticas públicas nas últimas décadas levou a instituição a um quadro crítico 
no que se refere à modernização de suas instalações, a preservação do acervo e a disponibilidade de produtos e serviços, incluindo a publicação de bibliografia nacional.

De acordo com Machado (2003, p. 61), a bibliografia nacional deve ser entendida "como um repertório que relaciona material bibliográfico de todos os assuntos, publicado dentro do território de determinado país". Deste modo, tem-se acesso, entre outras informações, a um quadro bastante aproximado do desenvolvimento do mercado editorial na região, sendo possível conhecer tendências ao longo da história, produzir estatísticas de crescimento e períodos de crise, fazer proposições sobre os interesses do público, entre outras questões que podem ser fruto de uma pesquisa, dependendo do detalhamento dos registros e possibilidades de busca e acesso.

Em 1886, o Brasil já possuía uma bibliografia nacional, o Boletim das Aquisições Mais Importantes feitas pela Biblioteca Nacional, com quatro sessões: imprensa, manuscrito, estampa e numismática. O boletim teve apenas três volumes e foi encerrado dois anos depois. Em 1918, a Biblioteca Nacional (BN) passou a publicar o Boletim Bibliográfico (Boletim Bibliographico da Bibliotheca Nacional do Rio de Janeiro), até que começou a enfrentar dificuldades no início da década de 1920 e deixou de ser publicado durante 30 anos descontínuos entre 1922 e 1972 (MACHADO, 2003, p. 62-64). Em seguida, sobreviveu até 1982, quando mudou o título para Bibliografia Brasileira. O novo nome permaneceu até 1995, quando a versão impressa foi definitivamente abandonada. Entre 1996 e 1997, a bibliografia nacional foi mantida em CD-ROM, mas a proposta não teve prosseguimento. A partir de então, a única forma de consultar os registros da Biblioteca Nacional é através do seu catálogo online (GRINGS; PACHECO, 2010, p. 80). O que se verifica é que o país nunca contou com a publicação de uma bibliografia nacional de forma duradoura, estável e periódica. O que se encontra para consulta são fragmentos de determinados anos do século XX, impedindo a elaboração de uma história de longa duração da nossa memória impressa e audiovisual.

O país ainda enfrenta inúmeros problemas no recebimento das obras. Muitas editoras solicitam o número de ISBN antes de ter a publicação pronta, algumas não o solicitam, embora seja obrigatório, outras usam o mesmo número em mais de um título; ou seja, mesmo o ISBN, criado para garantir um maior controle das publicações, não tem sido suficiente para o rastreamento do que se produz no Brasil. Pior, uma quantidade significativa de pequenas editoras não enviam a sua produção à $\mathrm{BN}$ tanto por desconhecimento de sua obrigatoriedade 
O catálogo editorial e a bibliografia como fontes de pesquisa: avanços e desafios na era digital

quanto para não arcar com o custo da tarifa postal, que pode atingir altos valores sobretudo para empresas distantes do Rio de Janeiro (GRINGS; PACHECO, 2010, p. 84-85). Fonseca (1972, p. 11-12) já alertava no início da década de 1970 que o depósito legal não era realizado por "grande parte dos editores e impressores".

Com falta de pessoal, a catalogação dos materiais recebidos pode demorar anos. Tornou-se praticamente impossível realizar buscas no catálogo online ao menos para os registros dos últimos dois anos. Caixas de materiais se acumulam nas dependências da BN aguardando o devido tratamento documentário. O excesso de documentos, a idade das instalações e algumas reformas prejudicam a garantia das melhores condições de preservação e conservação. A gravidade da situação levou as autoras Grings e Pacheco (2010, p. 86) a concluírem que "a retomada da publicação impressa da Bibliografia Brasileira ganhou um status secundário, diante de tantos outros problemas mais prementes no cotidiano da Biblioteca". A recomendação é para que se consulte o catálogo online da BN para acompanhar a produção nacional.

Em nossa pesquisa sobre livros de bolso, não podemos recorrer a esta ferramenta. Como nosso objeto era as coleções de bolso lançadas no Brasil nos últimos anos, não havia no catálogo online informações sobre os livros editados nos anos recentes devido ao atraso no tratamento documentário. Se em 2015, por exemplo, pesquisássemos sobre livros de 2012 da coleção L\&PM Pocket, da L\&PM, observaríamos que, embora os registros já tivessem sido disponibilizados, a imagem da capa ainda não teria sido incluída. Se procurássemos por obras de 2014, a situação seria muito mais crítica, já que nenhum título do ano anterior à escrita deste artigo estaria disponível no catálogo online, apesar do primeiro semestre de 2015 já ter transcorrido.

Mesmo em relação aos livros já inseridos ao acervo encontramos certos empecilhos. Em contato com a Biblioteca Nacional, fomos informados de que era possível consultar o acervo físico das coleções de bolso, porém era permitido solicitar apenas dois exemplares por vez. A cada consulta, seria necessário realizar um novo pedido aos bibliotecários. Uma condição que praticamente inviabiliza a pesquisa em coleções muito grandes. Em contraposição, na Bibliothèque Nationale de France, em Paris, é possível consultar vinte exemplares por dia, podendo ser pegos de uma única vez e em poucos minutos. A existência de uma bibliografia nacional corrente, disponibilizada alguns meses após a publicação de uma 
obra, e contendo um expressivo detalhamento de suas características, como realiza a British Library, seria de grande valia para pesquisas sobre o livro no Brasil na atualidade.

É inegável que o catálogo online possui diversas vantagens, como o acesso remoto, a rapidez com que os dados podem ser consultados, a maior possibilidade de realização de um catálogo universal, a facilidade com que os bibliotecários podem utilizá-lo como auxílio para a catalogação cooperativa e seleção de materiais. Entretanto, não se deve concluir que ele substitui sem perdas a publicação de repertórios bibliográficos, que devido à sua estrutura mais estável e pré-coordenada, facilita a leitura das informações, permite comparações entre edições e apresenta maior perenidade, pois mesmo em versão e-book, é visto como um produto acabado.

Uma das questões discutidas na $67^{\circ}$ Conferência da IFLA em 2011 (BEAUDIQUEZ, 2011, p. 7) foi a perenidade dos catálogos e bibliografias nacionais oferecidos na Web. Os seus registros devem ser preservados para a posterioridade, sendo recuperáveis as informações sobre o estado documental de um país em um determinado período de tempo. Porém, devido às próprias possibilidades de edição que a Web oferece, um registro pode ser alterado em data muito posterior sem que o consulente tenha conhecimento dessas modificações. Corre-se o risco de perder para sempre a visão de uma época sobre a sua memória informacional, pois mesmo imprecisões e erros de um repertório impresso podem ser fontes de pesquisa. Nesse sentido, permanece na Web a necessidade de explicitar minuciosamente os critérios utilizados na construção e edição de catálogos e bibliografias. 
O catálogo editorial e a bibliografia como fontes de pesquisa: avanços e desafios na era digital

\section{Considerações finais}

Como apontamos, a pesquisa sobre a produção livresca no Brasil atual enfrenta inúmeros obstáculos devido à falta de repertórios bibliográficos. Além do país não contar com uma bibliografia comercial corrente, a Biblioteca Nacional não publica uma bibliografia nacional desde 1997. Mesmo o catálogo online, que não substitui com eficiência a compilação de uma bibliografia, apresenta dificuldades para manter-se atualizado em razão dos problemas políticos e econômicas que a instituição vive. Se a inclusão de um título no catálogo online pode demorar mais de dois anos, não podemos dizer que o catálogo exerce a função de uma bibliografia corrente, pois, como vimos, entre as suas características está uma periodicidade definida, que deve ser curta, semanal ou mensal, preferencialmente.

As novas tecnologias trouxeram inúmeros benefícios, como a diminuição de custos para a divulgação de livros. Por meio dos catálogos editoriais online, um pesquisador pode obter inúmeras informações sobre a produção de uma editora, sendo uma importante fonte de pesquisa para análise de capas, preços, entre outros. Apesar disso, devido ao perfil comercial desses produtos e serviços, o controle de vocabulário e a preservação dos dados são bastante ineficazes. Quais os preços dos livros de uma coleção no ano 2000 se em seu site encontramos sempre o valor atual? A atualização constante da Web sem a preocupação de arquivamento e disponibilização impossibilita boa parte de projetos de pesquisa retrospectivos.

Nesse sentido, questionamos o futuro das pesquisas sobre o livro no Brasil. Como os pesquisadores das próximas décadas terão acesso aos registros da produção contemporânea? A resposta da Biblioteca Nacional ao problema, embora devam ser reconhecidos os seus esforços, ainda é muito tímida. Sem bibliografias correntes e retrospectivas, em conjunto com revistas profissionais que ofereçam discussões sobre o atual mercado editorial, tanto em uma perspectiva mercadológica como acadêmica, corremos o risco de perder para sempre parte de nossa memória social. 


\section{Referências}

BEAUDIQUEZ, M. Guide de bibliographie générale: méthodologie et pratique. München; New York; London; Paris: Saur, 1983.

. Usages et utilité des bibliographies nationales: quelles perspectives? In:

INTERNATIONAL FEDERATION OF LIBRARY ASSOCIATIONS AND INSTITUTIONS COUNCIL AND GENERAL CONFERENCE, 67., 2011, Boston. Anais eletrônicos... Boston: IFLA, 2011. Disponível em: 〈http://archive.ifla.org/IV/ifla67/papers/114-199f.pdf>. Acesso em: 22 jul. 2015.

BRASIL. Lei $\mathrm{n}^{\circ}$ 10.994, de 14 de dezembro de 2004. Dispõe sobre o depósito legal de publicações, na Biblioteca Nacional, e dá outras providências. Diário Oficial da União, Brasília, DF, 2004. Disponível em: 〈http://www.planalto.gov.br/ccivil_03/_ato20042006/2004/lei/110994.htm>. Acesso em: 21 jul. 2015.

BRITISH library sparks Amazon row. BBC News, London, 17 Oct. 2011. Disponível em: <http://www.bbc.com/news/entertainment-arts-15332307>. Acesso em: 14 jul. 2015.

CALDEIRA, P. T.; CARVALHO, M. L. B. O problema editorial da bibliografia brasileira corrente. Revista Brasileira de Biblioteconomia e Documentação, São Paulo, v. 13, n. 3/4, p. 210-216, jul./dez. 1980.

CAMPELLO, B. Introdução ao controle bibliográfico. 2. ed. Brasília: Briquet de Lemos, 2006.

FONSECA, E. N. Bibliografia brasileira corrente: evolução e estado atual do problema. Ciência da Informação, Rio de Janeiro, v. 1, n. 1, p. 9-14, 1972. Disponível em: <http://revista.ibict.br/ciinf/index.php/ciinf/article/view/1651/1259>. Acesso em: 22 jul. 2015.

GRINGS, L.; PACHECO, S. A Biblioteca Nacional e o Controle Bibliográfico Universal: situação atual e perspectivas futuras. InCID: Revista de Ciência da Informação e Documentação, Ribeirão Preto, v. 1, n. 2, p. 77-88, jul./dez. 2010. Disponível em: <http://www.revistas.usp.br/incid/article/view/42321/45992 >. Acesso em: 21 jul. 2015.

MACHADO, A. M. N. Informação e controle bibliográfico: um olhar sobre a cibernética. São Paulo: Unesp, 2003.

MALCLÉS, L.-N. La bibliographie. Paris: Presses Universitaires de France, 1956.

URBANO SALIDO, C. Bibliografía comercial y distribución de libros en España: diez años de evolución y cinco de Internet. Bibliodoc: anuari de biblioteconomia, documentació i informació, Catalunya, p. 167-186, 2000. Disponível em:

<http://www.raco.cat/index.php/Bibliodoc/article/view/16629/16470>. Acesso em: 18 jul. 2015 .

WENZ, R. L'avenir des catalogues: formats, données, outils, usages. 2009. 107 f. Mémoire d'étude (Master) - École Nationale Supérieure des Sciences de L'Information et des Bibliothèques, 2009. Disponível em: <http://www.enssib.fr/bibliothequenumerique/documents/21205-1-avenir-des-catalogues.pdf>. Acesso em: 14 jul. 2015. 